Post-implementation, 94\% of parents understood why their baby was on antibiotics and $88 \%$ had knowledge of antibiotic duration. $95 \%$ of parents found the leaflet useful with an increase of $20 \%$ of parents feeling confident about going home $(95 \%)$ see table 1.

\begin{tabular}{llll}
\hline Abstract G133(P) & Table 1 & & \\
\hline Questions & $\begin{array}{l}\text { Pre- } \\
\text { implementation of } \\
\text { Leaflet }\end{array}$ & $\begin{array}{l}\text { Post- } \\
\text { implementation of } \\
\text { leaflet }\end{array}$ & $\begin{array}{l}\text { Improvement } \\
\text { percentage }\end{array}$ \\
\hline $\begin{array}{l}\text { Understanding of why } \\
\text { on Antibiotics }\end{array}$ & $72 \%$ & $94 \%$ & $22 \%$ \\
$\begin{array}{l}\text { Confidence going home } \\
\text { Knowledge of antibiotic }\end{array}$ & $75 \%$ & $95 \%$ & $20 \%$ \\
duration & $29 \%$ & $88 \%$ & $59 \%$ \\
\hline
\end{tabular}

Conclusion Following introduction of our leaflet there has been an improvement in parental understanding and confidence going home. This in turn has led to an overall increase in parental satisfaction of their baby's care.

\section{G134(P) IMPROVING COMPLIANCE WITH NATIONAL GUIDELINES FOR EARLY ONSET NEONATAL SEPSIS}

T MacCarrick, A Magee, S Jones, E Gravell, P Davies, A Abelian. Paediatrics, Wrexham Maelor Hospital, Wrexham, UK

\subsection{6/archdischild-2018-rcpch. 130}

Aim An audit of compliance with NICE guideline CG149 for the management of early onset neonatal sepsis (EONS) undertaken at this hospital indicated underperformance with respect to duration of antibiotic treatment and choice of benzylpenicillin dose. A re-audit was carried out to evaluate the impact of measures introduced to improve compliance, with a particular focus on duration of antibiotic treatment.

Method Results of the initial audit were presented to the department, leading to the selection of champions for change. An intervention strategy was devised, which comprised of introducing a new section to the neonatal handover list, whereby date and time when repeat CRP and review of blood cultures should take place was clearly documented, together with results as they became available. This intervention was introduced at a departmental meeting, and received enthusiasm from junior doctors and consultants. Both audits were retrospective, spanning 12 months and 5 months respectively. Data were retrieved from case notes and the Trust's electronic laboratory management system.

Results The findings presented in the table 1 show that;

1. audits analysed $>75 \%$ of the cases of suspected EONS;

2. proportion of babies receiving $\leq 48$ hours of antibiotics increased from $18.5 \%$ to $69 \%$;

3. proportion of babies receiving a full 7 day course of treatment increased from $35 \%$ to $82 \%$;

4. compliance with benzylpenicillin dosing increased to $100 \%$.

\begin{tabular}{|c|c|c|c|}
\hline & $\begin{array}{l}\text { Original } \\
\text { Audit } \\
\text { (12 months) }\end{array}$ & $\begin{array}{l}\text { Re-audit } \\
\text { (5 months) }\end{array}$ & $p^{*}$ \\
\hline Babies tested for suspected EONS, $\mathrm{n}$ & 204 & 106 & \\
\hline Casenotes reviewed, n (\%) & $159(78)$ & $80(75.5)$ & 0.95 \\
\hline $\begin{array}{l}\text { Babies without sepsis receiving } \leq 48 \text { hours of } \\
\text { antibiotics, } \%\end{array}$ & 18.5 & 69 & $<0.0001$ \\
\hline $\begin{array}{l}\text { Babies with sepsis receiving } 7 \text { days of } \\
\text { antibiotics, } \%\end{array}$ & 35 & 82 & 0.02 \\
\hline $\begin{array}{l}50 \mathrm{mg} / \mathrm{kg} \text { dose of benzylpenicillin used for } \\
\text { meningitis only,\% }\end{array}$ & 0 & 100 & $<0.0001$ \\
\hline
\end{tabular}

Conclusion Introducing a robust system for ensuring the timely review of CRP and blood culture results has improved overall compliance with NICE guidelines, and in particular, has significantly reduced the number of babies receiving inappropriate durations of antibiotic treatment.

\section{G135(P) CHANGING LOCAL POLICY ON INTRAVENOUS FLUID CHOICE; IMPROVING SAFETY, COST-EFFECTIVENESS AND COMPLIANCE WITH BEST PRACTICE}

T MacCarrick, R Ellis, N Nelhans. Wrexham Maelor Hospital, Wrexham, UK

\subsection{6/archdischild-2018-rcpch.131}

Aim Using isotonic solution is considered best practice in the treatment of most children requiring intravenous fluids, in accordance with NICE guideline NG29. We observed that paediatric patients in this hospital frequently received $0.45 \%$ saline with additional glucose \pm potassium for maintenance. Other fluid preparations frequently prescribed for children included $0.9 \%$ saline and Hartmanns Solution. Our aim was to develop a new guideline for intravenous fluid prescription which conformed to best practice and streamlined choice of solution.

Methods A review of evidence regarding use of isotonic fluids in paediatrics was undertaken. Based on this, the feasibility of introducing PlasmaLyte (with and without 5\% glucose) was explored. Information concerning licensing, safety and costcomparison with intravenous solutions currently used in the trust was reviewed. The acceptability of PlasmaLyte within the regional paediatric network was established. This information was presented to key stakeholders, followed by a proposal to introduce PlasmaLyte as the fluid of choice in all paediatric patients in the trust, unless specifically contraindicated.

Results PlasmaLyte is a balanced crystalloid licensed for intravenous use (with and without 5\% glucose) in paediatrics, for bolus and maintenance infusion. An emerging body of evidence supports its clinical superiority when compared to other fluid preparations. There are, however, certain conditions, for example pyloric stenosis, in which PlasmaLyte is contraindicated. Although more expensive than saline solutions, taking into account the frequency of use of saline with additives, which is considerably more expensive, overall cost-comparison 